\title{
Exploring Continuity of Care in Patients with Alcohol Use Disorders Using Time-Variant Measures
}

\author{
S.C. de Vries A.I. Wierdsma \\ Department of Psychiatry, O3 Research Centre Mental Health Care, Erasmus MC, Rotterdam, The Netherlands
}

\section{Key Words}

Alcohol $\cdot$ Continuity of care $\cdot$ Long-term follow-up $\cdot$ Motivation to treatment - Sociodemographic profile . Substance abuse treatment $\cdot$ Time trends $\cdot$ Treatment retention

\begin{abstract}
Background/Aims: We used time-variant measures of continuity of care to study fluctuations in long-term treatment use by patients with alcohol-related disorders. Methods: Data on service use were extracted from the Psychiatric Case Register for the Rotterdam Region, The Netherlands. Continuity measures were calculated for each day over a 2-year observation period. Repeated measures analysis was used to identify factors that influence continuity of care over time. Results: Continuity of care was higher for patients with more severe disorders. Though quantity of care was high for patients with long problem history during the first year of treatment, it decreased strongly in the second year. The intervals between treatment contacts were shorter for women, especially young ones, than for men. Conclusion: Timevariant measures showed differences in continuity of care that would not have been revealed if more aggregated measures of service use had been used.
\end{abstract}

Copyright $\odot 2008$ S. Karger AG, Basel
(C) 2008 S. Karger AG, Basel

$1022-6877 / 09 / 0151-0019 \$ 26.00 / 0$

Fax +41613061234

E-Mail karger@karger.ch

www.karger.com
Accessible online at:

www.karger.com/ear

\section{Introduction}

Eight percent of the Dutch population meets the criteria for alcohol abuse or alcohol dependence [1]. Only 10\% of these excessive drinkers receive any kind of substance abuse treatment. Due to the chronic, relapsing nature of the disorder [2] and to the long time between start of symptoms and help seeking [3], treatment of alcohol use disorders is a time-consuming process [4].

Many studies on substance abuse treatment have stressed important links between treatment duration and treatment retention, showing that longer treatments are related to better outcomes [5] and a lower risk of readmission $[6,7]$. However, the relationship between long treatment periods and positive outcome is not without controversy [8]. Several studies have also examined the relationship between patient characteristics and treatment duration, finding that demographic characteristics were more predictive for length of stay in treatment than drug use characteristics [9], and that higher problem severity, as well as higher age, unemployment, and being male were often associated with longer treatment episodes [9, 10]. Other studies suggested that longer treatment is related to lower problem severity [11] and being female [12]. These contradictory findings may be explained by different treatment approaches, treatment settings, national variations in treatment systems and patient case mixes. 
Another important aspect in the study of treatment careers is intensity of care, unemployed patients and those with severe drinking problems being more likely to receive inpatient alcohol treatment $[13,14]$ and to benefit more from inpatient care than from outpatient care [15]. The odds of receiving inpatient care are also related to the source of referral. Self-referred patients and those referred by an alcohol or drug treatment provider are more likely to receive inpatient care than those referred by the criminal justice system [13]. A possible explanation for this may lie in the higher sense of urgency about the need for treatment, patients who were highly motivated to get treatment having higher odds of being admitted to inpatient care [14].

Although the intensity of substance abuse treatment is often dichotomized into inpatient and outpatient care, treatment of alcohol disorders often involves multiple types of care. Also, because of the chronic and relapsing nature of the disorder, multiple treatment episodes are often needed to achieve long-term recovery [16], and should not be seen as failed efforts [11]. It is therefore important to study patterns of treatment utilization over a long period of time, and to focus simultaneously on the duration and intensity of treatment.

To provide an extensive overview of treatment utilization patterns that took account of intensity and length of treatment, we used three time-variant measures of continuity of care as proposed by Fortney et al. [17]: frequency, quantity and variety of care. Continuity of care is associated with better quality of care $[18,19]$ and has been on the political and social agenda worldwide for many years [20]. In the United Kingdom, continuity of care was identified as a priority theme for the R\&D program of the National Health Service [21]. By using time-variant continuity of care measurements, we expected to find longterm, frequent use of treatment, and less intensive treatment later in time. Furthermore, we explored differences in treatment patterns between patient subgroups.

\section{Methods}

\section{Subjects}

We selected data on mental health services use by patients who in 2003 started treatment at the regional addiction treatment centre and who were living in the municipality of Rotterdam. All patients had alcohol use as primary problem. A total of 848 patients was included, $75.9 \%$ of them were male. Mean age at start of the treatment was 45.6 years (SD 11.1). These numbers are in line with the Dutch figures on the proportion of patients with alcohol-related disorders in outpatient care $(75 \%$ male, mean age 44) [22].

\section{Procedure}

Data were obtained from the Psychiatric Case Register for the Rotterdam Region, which contains continuous, person-linked information on the use of mental health services in a catchment area of 1.2 million inhabitants. For this study, we used data from the regional addiction treatment centre, which provides treatment for all kinds of substance abuse disorders. Treatment is free of charge and ranges from counselling to inpatient treatment. Contacts were collected for each individual patient over a period of 2 years after the first contact. There are no private treatment facilities of importance in the area.

The dataset included demographic information (e.g. age and gender), hospitalization days or contact dates, type of care, and information on problem severity and duration of the alcohol disorder before entering treatment. Treatment length was defined as the number of days between the first and the last contact during the 2 -year observation period. Clinical variables were severity of the disorder and problem history, i.e. duration of alcohol problems before entering treatment. The severity measure was based on the Addiction Severity Index (ASI) [23], which defines severity as need for treatment. Scores ranged from 0 to 9 , score 6 or higher indicating a considerable problem for which treatment is necessary. We dichotomized the score into severe disorders (ASI $>6$ ) and less severe disorders (ASI $\leq 6)$. Problem history was dichotomized into longer and shorter than 10 years.

\section{Continuity of Care Measurements}

The measures of continuity of care were based on the following dimensions: timelines of service use (frequency), the intensity of the services received (quantity), and the comprehensiveness of the services (variety). Although Fortney et al. [17] described two more measures of continuity of care - location consistency of care (number of facilities) and the receipt of case management - we disregarded these, as we did not have detailed information on treatment facilities and types of outpatient treatment.

Frequency, quantity, and variety of care were calculated for each day in the 2-year observation period. Quantity and variety were calculated using a 90-day moving window by counting the number of contacts and number of types of care in this period. The following types of care were distinguished [24]: (1) shortterm clinical care, (2) long-term clinical care, (3) other clinical care (e.g. sheltered residences), (4) daycare, (5) homecare, (6) rehabilitation, (7) supported activities, (8) emergency contacts, (9) psychotherapy, and (10) other outpatient contacts. Quantity was measured by counting the number of contacts in this 90 -day period. Frequency was measured by counting the number of days since the last contact. This provided information on temporal gaps in service use. Because of constraints imposed by statistical analysis procedures, all three continuity measurements were summarized in 24 monthly averages.

\section{Statistical Analysis}

Continuity of care was analyzed using GLM repeated measures with time as within-subjects factor. Post-hoc comparisons were performed using Bonferroni adjustment for multiple comparisons. We added problem severity and problem history as between-subjects factors, including the interaction between time and these variables to measure differences between the groups over time. To examine whether continuity of care was influenced by age and gender, we carried out MANCOVA repeated analysis 
Table 1. Patient characteristics

\begin{tabular}{ll}
\hline Male, \% & 76 \\
Age, years & 45.8 \\
Dutch origin, \% & 84 \\
Married, \% & 26 \\
Problem severity (mean ASI score) & 4.98 \\
Problem history >10 years, \% & 52 \\
Treatment length, days & 302 \\
Treatment length <90 days, \% & 35 \\
\hline
\end{tabular}

for age and gender as main effects, adding problem severity and problem history as covariates. The Huyn-Feldt correction was applied if the sphericity assumption was not met. Analyses were performed using SPSS 11.5 for Windows; $\mathrm{p}<0.05$ was considered significant.

\section{Results}

\section{Patient Characteristics}

The demographic and substance use characteristics of the patients included in this study are summarized in table 1. Most patients were male, of Dutch origin, and had had alcohol problems for more than 10 years before entering treatment. Problem history differed according to gender, $44 \%$ of women and $55 \%$ of men having had drinking problems for more than 10 years $\left(\mathrm{df}=1, \chi^{2}=6.311, \mathrm{p}=\right.$ 0.012 ). Problem history also differed by age: compared to their younger counterparts, more older patients $(>45$ years) had a problem history spanning more than 10 years $\left(\mathrm{df}=1, \chi^{2}=21.215, \mathrm{p}=0.000\right)$. Problem severity scores and treatment length did not differ with age and gender.

\section{Continuity of Care}

Figure 1 shows the course of continuity of care measured by frequency, quantity and variety of care. The main effect of time was significant for all three measures of continuity of care $(\mathrm{p}=0.000)$. Time gaps between treatment contacts increased each month (fig. 1). Quantity of care decreased after approximately 4 months, averages ranging from 7.0 (SD 0.50) contacts in the fourth month to 5.1 (SD 0.50) in the eighth month. After this period, the number of contacts further decreased to 3.0 (SD 0.37), the decline by month no longer being statistically different. Variety of care was highest in the first 3 months of treatment, and decreased significantly from 1.3 (SD 0.20) in month 3 to 0.64 (SD 0.25) in month 7. Any further decline was not statistically significant.

Continuity of Care in Patients with Alcohol Use Disorders
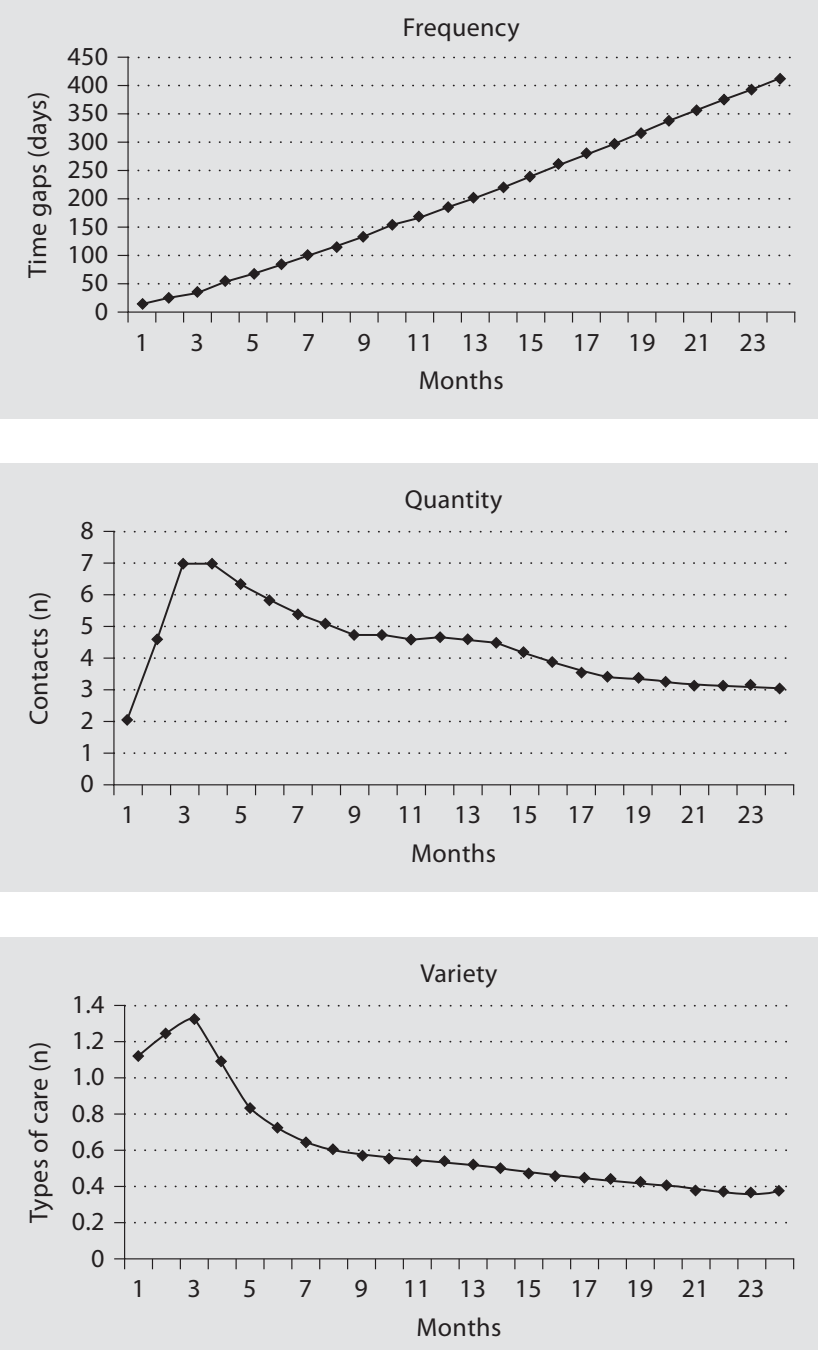

Fig. 1. Measurements of continuity of care: frequency, quantity and variety.

\section{Clinical Factors}

The severity of the disorder had a main effect on all three measures of continuity of care. Intervals between treatment contacts were shorter for patients with severe alcohol disorders (frequency, $\mathrm{F}(1)=9.017, \mathrm{p}=0.003$ ), who also had more contacts (quantity, $\mathrm{F}(1)=30.778, \mathrm{p}=0.000$ ) and received a greater variety of types of care (variety, $\mathrm{F}(1)=11.402, \mathrm{p}=0.000)$. There were no main effects of problem history on these measures of continuity of care.

Problem history and time were found to interact with quantity of care $(\mathrm{F}(4.3)=3.316, \mathrm{p}=0.008)$, and disorder severity and time to interact with frequency of care $(\mathrm{F}(1.7)=6.261, \mathrm{p}=0.004)$. Patients with long-lasting al-

Eur Addict Res 2009;15:19-24 


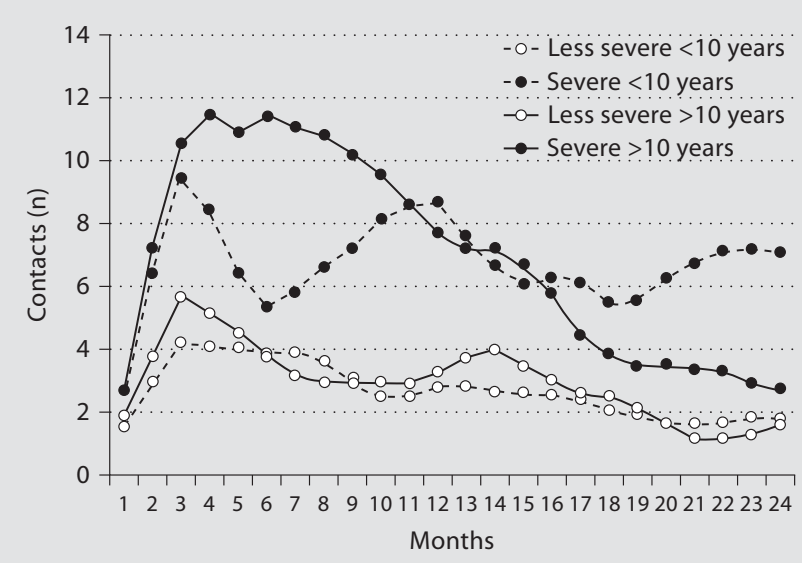

Fig. 2. Interaction between problem severity, time, problem history and quantity of care.

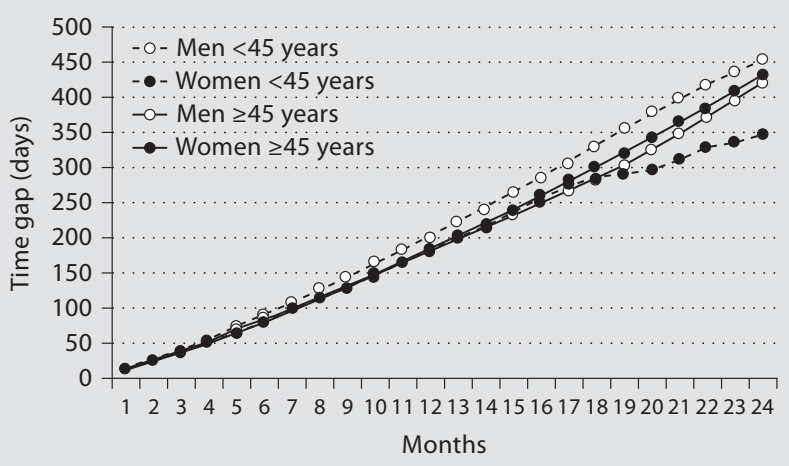

Fig. 3. Interaction between age, gender, and frequency of care.

cohol problems had more treatment contacts in the first 10 months of treatment but fewer contacts in the last half year of treatment than patients with shorter problem histories.

There was an interaction between time, problem history, and problem severity as independent variables and quantity of care as dependent variable $(\mathrm{F}(4.3)=3.075$, $\mathrm{p}=0.013$ ) (fig. 2). Patients with severe alcohol disorders and shorter problem history had more contacts throughout the 2-year period. In contrast, for patients with severe alcohol disorders and longer problem histories, the number of contacts declined during the second year of treatment.

\section{Gender and Age Differences}

Women received more different types of care than men $(F(1)=6.971, p=0.009)$. Age interacted with gender: while older women did not differ from older men, young women had more variety in care than younger men $(\mathrm{F}(1)=4.485, \mathrm{p}=0.035)$.

An interaction was found between age, gender, and time as independent variables and frequency of care as dependent variable. At the end of the 2-year treatment period, the time gaps between two successive contacts were smaller for women than for men $(\mathrm{F}(4.7)=4.677, \mathrm{p}=$ $0.014)$. There was no gender difference in the older age group (fig. 3).

\section{Discussion}

\section{Principal Findings}

By using time-variant measures of continuity of care and by taking a long observation period it was possible to longitudinally examine patterns of care of patients with alcohol use disorders. In general, patients received a high quantity and variety of care in the first 3 months of treatment. After that, variety dropped rapidly, probably because they had been assigned to a particular treatment program after a period of intake and problem investigation. Within this period, a substantial number of patients also ended or dropped out of treatment.

Analyses of patient subgroups revealed differences in continuity of care in relation to problem severity, problem duration, age and gender. Patients with severe alcohol disorders had more treatment contacts, smaller time gaps between contacts, and more variety in care. There was an interaction between time and problem history: in the first year, patients with long-lasting alcohol problems had many contacts, but during the second year the number of contacts fell below that of patients with shorter history of problems. Women, especially young women, had more frequent contacts than men.

\section{Strengths and Limitations}

This study was based on a relatively large patient sample, a 2-year follow-up period that was determined individually for each patient, and both inpatient and outpatient care. These enabled us to examine differences between treatment careers in several patient subgroups and to provide a comprehensive illustration of the course of treatment.

Due to the relapsing nature of the disorders and the fact that many patients need multiple treatment episodes 
in order to achieve remission, it is important to use timevariant measures of continuity of care when studying addiction disorders. This study showed fluctuations in the use of care over time which would not have been revealed if more aggregated measures of treatment utilization had been used.

One of the limitations of this study is the lack of outcome measures. Previous studies have shown that higher continuity of care is related to better treatment outcomes $[25,26]$. It would therefore be interesting to examine which measures of continuity of care were associated with higher recovery rates in the patient subgroups we examined.

Another limitation is that we had no data on the use of unofficial treatment settings, such as Alcoholics Anonymous and other support groups, which could play an important role in recovery [27] and in achieving better long-term alcohol-related outcomes after treatment [28]. However, in The Netherlands the number of patients attending such support groups is relatively small [29].

\section{Relation to Other Studies}

While many studies of alcohol treatment have focused on gender differences, more frequent treatment participation of women is not a consistent finding. For example, McCaul et al. [9] found that women had poorer treatment retention and participation than men. Taken together, a plausible explanation is that gender differences are involved in other factors that predict treatment patterns [30, 31], e.g. race, marital status, psychiatric comorbidity [11]. Current treatment programs differ in the way in which they account for these factors.

In our study we found that whereas the amount of treatment received by patients with a shorter history of problems remained relatively stable, visits to the treatment centre by patients with severe, long-term alcohol problems dropped dramatically during the second year of treatment. A possible explanation for these findings could be that long problem duration is an indication of low motivation for treatment. This would be consistent with other studies showing that longer treatment retention was associated with high motivation [32]. Other possible explanations of dropout could be a higher proportion of treatment failure in this patient group, or resignation within the staff. More research is needed to clarify these issues.

\section{Implications}

This study showed that, after controlling for clinical variables, continuity of care in alcohol treatment is affected by demographic factors. Treatment participation may be enhanced by matching patients to treatment on the basis of their individual needs and characteristics, and by developing specialized treatment programs for patient subgroups.

The majority of patients entered treatment after more than 10 years of alcohol problems. Since early intervention and treatment entry are related to better outcomes [33], more efforts are needed in three areas: (1) people should be motivated to get help early, (2) the barriers they experience while and before they seek help should be established, and (3) long-term aftercare should become standard practice in treating patients with alcohol disorders. With regard to the latter, telephone-based aftercare and support groups might be effective and relatively inexpensive types of stepdown treatment [25, 28].

To examine the relationship between treatment outcome and continuity of care, future studies on alcohol treatment patterns should include outcome measures and patient satisfaction questionnaires. Time-variant measures, which proved useful to study the long-term treatment of these patients, will help create greater insight into treatment patterns of patients with other long-lasting psychiatric disorders.

\section{References}

1 Verdurmen J, Monshouwer K, Van Dorsselaer S: Bovenmatig drinken in nederland: uitkomsten van de 'Netherlands Mental Health Survey and Incidence Study' (NEMESIS)/Excessive drinking in the Netherlands, results of the Netherlands Mental Health Survey and Incidence Study (NEMESIS). Utrecht, Bureau NDM, 2003.

12 Leshner AI: Addiction is a brain disease, and it matters. Science 1997;278:45-47.
Kessler RC, Aguilar-Gaxiola S, Berglund PA, Caraveo-Anduaga JJ, DeWit DJ, Greenfield SF, Kolody B, Olfson M, Vega WA: Patterns and predictors of treatment seeking after onset of a substance use disorder. Arch Gen Psychiatry 2001;58:1065-1071.

4 O'Brien CP: Treatment of alcoholism as a chronic disorder. Alcohol 1994;11:433-437.
5 Hubbard RL, Craddock SG, Anderson J: Overview of 5-year follow-up outcomes in the drug abuse treatment outcome studies (DATOS). J Subst Abuse Treat 2003;25:125134

6 Luchansky B, He L, Krupski A, Stark KD: Predicting readmission to substance abuse treatment using state information systems. The impact of client and treatment characteristics. J Subst Abuse Treat 2000;12:255270 . 
7 Swindle RW, Phibbs CS, Paradise MJ, Recine BP, Moos RH: Inpatient treatment for substance abuse patients with psychiatric disorders: a national study of determinants of readmission. J Subst Abuse 1995;7:79-97.

8 Luty J: What works in alcohol use disorders. Adv Psychiatr Treat 2006;12:13-22.

$\checkmark 9$ McCaul ME, Svikis DS, Moore RD: Predictors of outpatient treatment retention: patient versus substance use characteristics. Drug Alcohol Depend 2001;62:9-17.

-10 Timko C, Moos RH: Symptom severity, amount of treatment, and one-year outcomes among dual diagnosis patients. Adm Policy Ment Health 2002;30:30-54.

- 11 Hser YI, Polinsky ML, Maglione M, Anglin MD: Matching clients' need with drug treatment services. J Subst Abuse Treat 1999;16: 299-305.

12 Fletcher BW, Broome KM, Delany PJ, Shields J, Flynn PM: Patient and program factors in obtaining supportive services in datos. J Subst Abuse Treat 2003;25:165-175.

13 Duffy SQ, Zarkin GA, Dunlap LJ: Do client characteristics affect admission to inpatient versus outpatient alcohol treatment in publicly monitored programmes? In Council CL (ed): Health Services Utilization by Individuals with Substance Abuse and Mental Disorders. Rockville, Substance Abuse and Mental Health Services Administration, Office of Applied Studies, 2004, pp 53-78.

14 Gregoire TK: Factors associated with level of care assignment in substance abuse treatment. J Subst Abuse Treat 2000;18:241-248.

15 Rychtarik RG, Connors GJ, Whitney RB, McGillicuddy NB, Fitterling JM, Wirtz PW: Treatment settings for persons with alcoholism: evidence for matching clients to inpatient versus outpatient care. J Counsel Clin Psychol 2000;68:277-289.
16 Dennis ML, Scott CK, Funk R, Foss MA: The duration and correlates of addiction and treatment careers. J Subst Abuse Treat 2005; 28:S51-S62.

-17 Fortney J, Sullivan G, Williams K, Jackson C, Morton SC, Koegel P: Measuring continuity of care for clients of public mental health systems. Health Serv Res 2003;38:1157-1176.

18 Gill JM, Mainous Iii AG, Nsereko M: The effect of continuity of care on emergency department use. Arch Fam Med 2000;9:333338.

19 Christakis DA, Wright JA, Zimmerman FJ, Bassett AL, Connell FA: Continuity of care is associated with high-quality care by parental report. Pediatrics 2002;109:e54.

20 Haggerty JL, Reid RJ, Freeman GK, Starfield $\mathrm{BH}$, Adair CE, McKendry R: Continuity of care: a multidisciplinary review. BMJ 2003; 327:1219-1221.

21 Freeman GK, Weaver T, Low J, De Jonge E, Crawford M: Promoting continuity of care for people with severe mental illness whose needs span primary, secondary and social care. London, National Coordinating Centre for NHS Service Delivery and Organisation R\&D (NCCSDO), 2002.

22 National Drug Monitor 2006. Utrecht, Netherlands Institute of Mental Health and Addiction, 2007.

23 Hendriks VM, Kaplan CD, Van Limbeek J, Geerlings P: The addiction severity index, reliability and validity in a Dutch addict population. J Subst Abuse Treat 1989;6:133141.

24 Dutch Healthcare Authority, 2008. http:// www.Nza.Nl/aanbieder/ggz/tarieven.

25 McKay JR, Lynch KG, Shepard DS, Pettinati HM: An examination of potential sex and race effects in a study of continuing care for alcohol- and cocaine-dependent patients. Arch Gen Psychiatry 2005;62:199-207.
26 Ritscher JB, Moos RH, Finney JW: Relationship of treatment orientation and continuing care to remission among substance abuse patients. Psychiatr Serv 2002;53:592-601.

27 Moos RH, Moos BS, Timko C: Gender, treatment and self-help in remission from alcohol use disorders. Clin Med Res 2006;4:163174.

28 Moos RH, Moos BS: Participation in treatment and alcoholics anonymous: a 16-year follow-up of initially untreated individuals. J Clin Psychol 2006;62:735-750.

29 Dutch Ministry of Health: Alcoholnota. Nota over intensivering van het alcoholmatigingsbeleid (2001-2003)/Alcohol memorandum. Report on Intensifying the Alcohol-Restrain Policy. The Hague, Dutch Ministry of Health, 2000.

30 Green A, Polen MR, Dickinson DM, Lynch FL, Bennett MD: Gender differences in predictors of initiation, retention, and completion in an HMO-based substance abuse treatment program. J Subst Abuse Treat 2002;23:285-295.

-31 Greenfield SF, Azzone V, Huskamp H, Cuffel B, Croghan T, Goldman W, Frank RG: Treatment for substance abuse disorders in a privately insured population under managed care: costs and services use. J Subst Abuse Treat 2004;27:265-275.

32 Schaefer JA, Ingudomnukul E, Harris AHS, Cronkite RC: Continuity of care practices and substance use disorder. Patients' engagement in continuing care. Med Care 2005;43: 1234-1241.

33 Moos RH, Moos BS: Sixteen-year changes and stable remission among treated and untreated individuals with alcohol use disorders. Drug Alcohol Depend 2005;80:337347. 